\title{
El paisaje en la poesía de José Ángel Valente
}

Espacio testimonial y espacio de deshacimiento

\section{Claudie Terrasson}

\section{(2) OpenEdition \\ Journals}

Edición electrónica

URL: http://journals.openedition.org/agedor/1489

DOI: 10.4000/agedor.1489

ISSN: 2104-3353

Editor

Laboratoire LISAA

Referencia electrónica

Claudie Terrasson, «El paisaje en la poesía de José Ángel Valente », L'Âge d'or [En línea], 10 | 2017,

Publicado el 14 enero 2019, consultado el 21 abril 2019. URL : http://journals.openedition.org/

agedor/1489; DOI : 10.4000/agedor.1489

Este documento fue generado automáticamente el 21 abril 2019.

L'Âge d'or. Images dans le monde ibérique et ibéricoaméricain 


\title{
El paisaje en la poesía de José Ángel Valente
}

\author{
Espacio testimonial y espacio de deshacimiento
}

Claudie Terrasson

\section{¿Presencia del paisaje en la obra valenteana?}

1 Este estudio se propone ilustrar una faceta poco difundida del decir poético de José Ángel Valente (Orense 1929-Ginebra 2000); se trata de abordar la faceta relativa a su postura de poeta del disenso mediante su relación con el paisaje. Hace falta primero precisar tal afirmación en cuanto atañe a la recepción de la obra valenteana hoy en día en Francia. Si bien se la leyó en los setenta y ochenta como la de un poeta si no comprometido por lo menos como poeta responsable y solidario, luego se impuso definitivamente la imagen del poeta místico y abstracto ${ }^{1}$. Abordaremos tal cuestión a través del prisma de representaciones paisajísticas viendo cómo Valente las elaboró en varios poemas pasando por fases de construcción o deconstrucción. En este estudio se entenderá la noción de paisaje como descripción o evocación de un entorno natural o urbano con las dimensiones culturales que van asociados con él. Así fue cómo Eduardo Martínez de Pisón lo definió en una conferencia inaugural al coloquio celebrado en Santiago de Compostela en 2016:

En geografía se ha denominado tradicionalmente "paisaje" a la configuración adquirida por los hechos territoriales y sólo en escasas ocasiones o de modo secundario o en momentos muy recientes se ha sumado a ello el importante peso de la cultura en ese concepto. Al contrario, en el ámbito artístico se viene entendiendo por paisaje exclusivamente su representación estética o el lugar estetizado. Sin embargo, en cualquiera de los dos casos, el paisaje integra otros contenidos y, por supuesto, los culturales, que son amplios, incluso morales, y todos ellos lo constituyen sobre su básica morfología. ${ }^{2}$

Quizás sorprenda evocar a Valente para cuestionar el paisaje ya que una primera lectura de su obra poética deja ver ocurrencias relativamente limitadas de paisajes principalmente en su primera etapa. Si se tuviera que citar el paisaje emblemático valenteano sería sin duda el desierto con el cual se abre su obra: "Cruzo un desierto y su 
secreta/ desolación sin nombre"3. Para la mayoría de los estudiosos desempeñan los escasos paisajes presentes en Punto cero una función principalmente testimonial. En los libros siguientes, de Material Memoria (recopilación de libros publicados entre 1979 y 1992) hasta el último Fragmentos de un libro futuro (2000), predomina como bien se sabe la estética de lo inconcluso, del desnudamiento y de la concentración. Sin embargo conviene recordar que ya asoma desde el libro inicial y se va acentuando cada vez más a partir de $\mathrm{El}$ inocente (1967-1970), de modo que el paisaje valenteano, a la manera de la pintura china, aparece en forma fragmentaria, aislada en el vacío circundante. Es puro esbozo que rehuye de la totalidad, y que se revela paradójicamente mediante su misma construcción sin acabar, es laberinto y juego entre lo visible e lo invisible:

(Homenaje a Klee)

El paisaje retiene

alrededor del pez inmóvil

toda la luz del fondo no visible. ${ }^{4}$

3 La crítica interpreta esta segunda fase de la obra como alejada de la postura testimonial inicial. Por eso suele considerar a José Ángel Valente como paradigma del poeta de lo absoluto, del verbo sagrado, heredero de los místicos (a los que dedicó de hecho varios estudios, llegando a editar la obra del quietista Miguel de Molinos), reduciendo así o ignorando su disconformidad cívica y su heterodoxia poética. Se le insertó en la categoría de la poesía del silencio. No me detendré aquí en la cuestión de la invalidez ni de sus límites de tal categoría ${ }^{5}$. Lo que sí manifiesta esta categorización es la dificultad para el estudioso de abarcar la complejidad de una obra múltiple y fundamentalmente heterodoxa con vertientes varias, no solo poética sino teórica, crítica, y traductora también. Los postulados teóricos y críticos de Valente así como su dicción marcada radicalmente por la concentración, la parquedad, lo elíptico hacen que se lo lee como a un poeta hermético cuya caminar conduciría a una forma de abstracción. Veremos con su último libro cómo la estética del deshacimiento nunca excluyó lo inmediato sino que al revés, dio cuenta de su presencia y supuso encontrar al otro.

Importa analizar pues cómo funciona el paisaje en la poesía valenteana, y qué significado permite elaborar.

Nuestro estudio parte de una selección de poemas en que aparece un referente, o sea un elemento fuerte de determinación.

\section{Función testimonial del paisaje}

6 Nuestro estudio se interesará aquí por la paradójica presencia de un topónimo tras el cual está un paisaje identificable, cuando toda la creación valenteana reivindica la indeterminación absoluta. Lo postula tajantemente el epígrafe programático con el que se inicia Punto cero: "La palabra ha de llevar al punto cero, al punto de la indeterminación infinita, de la infinita libertad". Esta voz anónima plantea la indeterminación como condición sine qua non de una palabra libre. Lejos de abogar por una poesía ajena a su tiempo y a lo real, ajena a la preocupación por el aquí y el ahora, Valente precisa su postura estética y ética glosando la frase de Lautréamont: "Un poeta debe ser más útil/ que ningún ciudadano de su tribu"7. 


\section{Paisajes de Silos: construcción y deconstrucción}

7 Un topónimo famoso asociado a un paisaje conocido aparece con el poema "Silos"8 que Valente publicó en el poemario La memoria y los signos (1960-1965)", ambos títulos parecen situarse pues lejos del epígrafe de Punto cero, en cuanto al poema merece que lo tengamos en consideración por ser a priori una excepción mayúscula al ideal estético y ético de Punto cero. Por otra parte, para cualquier lector es obvio que se sitúa en una relación de intertextualidad con el famosísimo soneto de Gerardo Diego, "El ciprés de Silosv"

El título valenteano no solo no obedece al postulado de la indeterminación sino que denota un lugar fácilmente identificable dada su mucha fama literaria e histórica. El topónimo Silos remite un pasado histórico canónicamente presentado como clave por la historiografía más tradicionalista: el de la formación de Castilla como bastión de la Reconquista y cristiandad:

El monasterio de Silos es un monasterio muy antiguo cuya fundación se hace remontar por tradición al rey Recaredo en 593. La primera documentación del monasterio de Silos, sin embargo, es del año 933, después de la toma de Carrazo y aparece en una carta de Fernán González.... ${ }^{11}$

Con lo cual se relaciona Silos con varias figuras entre épicas, legendarias y literarias, pero ante todo son figuras que fundan la identidad castellana: Recaredo, el rey godo que al convertirse al cristianismo lo impuso, Fernán González el que supuestamente fundó Castilla siendo así él su primer héroe, Gonzalo de Berceo, el fundador de la literatura castellana al ser su "primer poeta" ${ }^{12}$ y por fin Santo Domingo de Silos, del cual sabemos que fue un personaje políticamente importante en tiempos de los reyes de Castilla y amigo del propio $\mathrm{Cid}^{13}$. Por consiguiente, no es de extrañar que Silos llegara a encarnar el ideal político y lingüístico de Castilla tal como lo construyeron los hombres del 98, ideal recuperado luego por la ideología del nacional catolicismo. Decir Silos equivale pues a exaltar la memoria de la identidad castellana concebida como la de la Reconquista triunfante, significa reivindicar una concepción marcadamente conservadora de España. Por eso interesa analizar cómo José Ángel Valente construyó la representación del paisaje silesiano, teniendo en cuenta que escribió su poema unos cuarenta años después del soneto de Gerardo Diego y sabiendo que "El ciprés de Silos"14 (1925) fue un texto ampliamente recuperado y difundido por la España nacional-católica. Es de suponer entonces que el texto de Diego funciona como hipotexto y contra modelo del de Valente, deconstruyendo éste la representación marcadamente religiosa e ideológica de aquél (enfatizada luego por la lectura que se hizo del soneto durante toda la dictadura) y reconstruyendo un paisaje alternativo y disconforme.

SILOS

Silos

La luz.

La Yecla: el socavado

corazón de la piedra

o la ascensión del aire.

Arriba

el agrio son quebrado de los grajos ${ }^{15}$

Éste es el primer tiempo del texto en el que se le propone al lector descubrir el espacio. El verso inicial es idéntica repetición del título, retoma su forma concentrada alrededor del solo topónimo: carece de cualquier determinante o indicio textual como si fuera una invocación más que una evocación. Es relevante que Valente haya suprimido cualquier 
referencia al paisaje religioso (monumento, claustro, ciprés) y le proponga al lector centrarse en el solo topónimo, instalando así un horizonte de expectativas y cierto misterio. A continuación, el lector se encuentra con una enumeración de elementos, visualmente dispersos por la página, creando esta forma fragmentada una impresión de sucesión algo caótica. Son toques descriptivos heterogéneos que no llegan a construir un paisaje coherente y ordenado; se suceden dentro de una dicción enteramente nominal que tampoco llega a elaborar una continuidad discursiva.

11 Primero aparece la luz; podría ser ésta el símbolo de la verdad y vida, símbolo anunciador del monasterio, espacio de espiritualidad y trascendencia y su ciprés emblemático de la fe y del arrobo místico. Las aliteraciones iniciales (Silos La luz. La Yecla) empiezan a sugerir la fluidez de un vuelo. Pero la irrupción inesperada de otro topónimo (la Yecla) introduce violentamente (con otras sonoridades) el paisaje de un desfiladero, destruyendo las sugerencias iniciales. Aunque asociado al monasterio de Silos por su proximidad geográfica, la Yecla se le opone por su carácter natural, salvaje, accidentado ${ }^{16}$. Este paisaje es el que va a concentrar la atención de la voz poética, apartando el paisaje religioso del monasterio.

12 Se observa que la construcción del paisaje natural compuesto de elementos primarios antitéticos ("piedra y aire") viene estructurada por un eje vertical (mediante la red léxica "ascensión, arriba"). Es de notar la equivalencia afirmada entre "socavado corazón" y “ ascensión del aire": las aliteraciones duras del sintagma "socavado corazón" contrastan con el semantismo del adjetivo (fragilidad). Se desprende del paisaje una sensación de peligro y ahogamiento que genera la necesidad física de salir para respirar. La expresión "la ascensión del aire" no encierra aquí ninguna connotación espiritual contrariamente al terceto de Diego orientado todo hacia el espacio celeste:

Cuando te vi señero, dulce, firme

qué ansiedades sentí de diluirme

y ascender como tú, vuelto en cristales. ${ }^{17}$

13 Es de notar cómo Valente descarta la denotación del cielo recurriendo al adverbio meramente espacial "arriba" y cómo lo asocia a la agresividad de aves de carroña descalificando de esa manera el simbolismo tradicional del cielo y del ave (dios, libertad, poesía): “Arriba/ el agrio son quebrado de los grajos". De nuevo, el poeta juega con la materia sonora de las palabras ("agrio, quebrado, grajos") para imposibilitar cualquier construcción de paisaje celestial. La insistencia en la verticalidad es relevante porque sistemáticamente se desvía el significado simbólico de la trascendencia que se le hubiera podido asociar. Por otra parte, para un lector de aquellos años sesenta tanto la palabra "arriba" como el valor simbólico de Silos no podía sino aludir al nacional catolicismo. De modo que es llamativo notar cómo desde el inicio del poema la voz lírica recusa por completo el paisaje que el topónimo solía convocar en la mente colectiva.

Sigue y se acentúa este proceso de destitución de lo religioso y divino cuando a continuación se sustituye el paisaje celeste por el espacio terrenal de los hombres.

Y en lo alto la tierra,

sola desde la altura,

capaz, enorme, terca, hasta lo lejos.

La extensión de la tierra. ${ }^{18}$

15 La formulación aparentemente paradójica, agudiza lo heterodoxo y transgresor de esta afirmación que invierte la jerarquía religiosa entre cielo y tierra, apuntando además el 
adjetivo "sola" la ausencia divina. Da lugar a la evocación solemne de un paisaje genérico ("la tierra"), designado por un sustantivo polisémico ("la tierra"), que abarca tanto lo concreto (la materia o el terreno destinado a cultivos) como la noción de nación o espacio donde uno nace. Cabe observar cómo súbitamente el ritmo cobra amplificación (se pasa de dos heptasílabos a un endecasílabo heroico) mientras los calificativos van elaborando una impresión cada vez más afirmada de potencia y fuerza: ("capaz, enorme, terca, hasta lo lejos"). Concluye esta primera fase de construcción del paisaje con un verso aislado en el que el nominalismo y la concisión condensan y agudizan tal sugerencia: "La extensión de la tierra." La expresión introduce ahora el eje de una horizontalidad ilimitada tanto a nivel del espacio como de la temporalidad ${ }^{19}$, y los blancos tipográficos que enmarcan el verso acentúan esta impresión.

Por eso, de repente en este paisaje-tiempo infinito surge la presencia humana: ésta reorienta la construcción del paisaje hacia lo histórico introduciendo una tonalidad trágica. Va a cobrar la palabra "tierra" un significado marcadamente social:

La mano, la matriz, el silo, el hondo

clamor rojizo de la tierra oscura,

de la tierra solar.

Amenazada

raíz, jamás vencida,

bajo un sol de injusticia. ${ }^{20}$

La estrofa ostenta una fuerte coherencia temática alrededor del sufrimiento humano generado por el trabajo continuo de la tierra; la evocación que pasa por procedimientos de enumeración, nominalismo, encabalgamientos, repeticiones plasma esta historia. La tierra inmensa (latifundio) se convierte en espacio de dura labor del hombre. Tanto la sinécdoque ("la mano") como la aliteración ("La mano, la matriz") designan al hombre trabajador como creador de vida y riqueza, por eso concluye la enumeración con el edificio que abriga tal riqueza ("el silo"). La homonimia "silo/ Silos" nada fortuita permite designar al clero como el que explota a los que trabajan, como partícipe de un sistema de dominación feudal connotado por el valor polisémico de "solar". Se sugiere que la tierra queda acaparada por los que dominan Por otra parte, juega posiblemente Valente con la polisemia del término silo, el cual designa también un espacio subterráneo donde se guardan misiles, haciendo del monasterio el símbolo de una lucha secular por la tierra ${ }^{21}$. De ahí que la palabra clave del trozo sea "clamor"22: connota tanto el sufrimiento físico y moral como la expresión de la rebeldía de la tierra personificada, auténtica encarnación de los ignorados ("la tierra oscura"). La metonimia afirma la simbiosis hombre-tierra y alcanza luego un paroxismo con la metáfora de la raíz, frágil y subterránea pero aún con vida, símbolo de la resistencia humana. Este paisaje construido por Valente revela un sistema social fundamentalmente injusto ("bajo un sol de injusticia" ${ }^{23}$ ). Descalifica definitivamente la imagen espiritual de Silos introduciendo una lectura histórica sumamente crítica del sistema agrario que oprime al hombre. Va a desarrollarla en la última estrofa en la que reintroduce un asomo de narratividad con dos verbos.

Pesa la luz. Gravita el eje ardiente

sobre el pecho del hombre,

sobre su sorda servidumbre

y el seco llanto de los siglos.

Silos

18 La dureza del ataque rítmico de los verbos y las sonoridades lo mismo que la anáfora realzan el semantismo del dolor. Mediante los verbos, se designa un movimiento de 
opresión que baja del mismo cielo y se le cuenta al lector una historia de esclavitud: aquí el paisaje se hace testimonio de una historia secular silenciada ${ }^{24}$, la de los olvidados y anónimos que sufren, de los hombres oprimidos cuyo dolor extremado se sugiere por el oxímoron "seco llanto". A la visión exaltadamente cristiana de Diego, opone Valente un paisaje portador de una historia social. Hace eco a los versos de Miguel Hernández sobre la explotación de los peones andaluces, víctimas de una forma de esclavitud hereditaria ${ }^{25}$. No obstante, difiere Valente en la construcción del paisaje: su dicción lo universaliza. Es interesante aproximar este paisaje silesiano de otro poema valenteano "Redoble por los kaiowás del Matogrosso del Sur" ${ }^{26}$ en que volvemos a oír semejantes palabras en una situación similar de peones oprimidos e incluso represaliados: "Fazendeiros de fazendas e mortes". Es relevante saber que tal poema pertenece al último libro Fragmentos de un libro futuro, lo que demuestra una continuidad en la denuncia peculiar e universalizante relativa a la cuestión agraria y más allá continuidad en la afirmación de la solidaridad humanan en la tierra ${ }^{27}$. Los peones del Matogrosso y los de Silos comparten una misma injusticia secular.

19 La reiteración final del topónimo Silos enlaza con la palabra anterior siglos mediante la rima y la paronomasia. Tales procedimientos permiten arraigar este lugar en el tiempo histórico, borrando la dimensión mítica y mística del monasterio para mejor señalar que éste no puede eximirse de la historia humana.

La antepífora permite recalcar una serie de significados: suena ahora el nombre del espacio con connotaciones muy alejadas de las del principio, hasta opuestas. Valente deconstruyó los valores canónicos atribuidos al paisaje de Silos invirtiéndolos. Silos ya no aparece como el lugar de arrobamiento espiritual como en Diego sino como espacio vital para el hombre, es pura tierra, materia que da vida. A la dinámica ascendente y espiritual del soneto de Diego, opone Valente un paisaje revelador de una historia social y humana de opresión. Descarta la épica castellana y la hagiografía para dejar testimonio de la microhistoria de los desconocidos y olvidados.

21 Esta oposición viene subrayada por el contraste formal, Valente juega con el contraste plástico entre ambos poemas: a la estructura equilibrada y regular del soneto opone una forma fragmentada (blancos, polimetría versos escalonados) que coincide con el proceso de deconstrucción del paisaje silesiano, más precisamente de la lectura que se puede hacer del paisaje. Procede a un aislamiento de cada elemento, atribuyéndolos de ese modo un existir absoluto, fuera de cualquier determinación dejándole al lector la tarea de ver cuanto no se dice. Al discurso elaborado por Diego según las pautas canónicas de retórica (distributio, elocutio...) y las del esquema petrarquista (sólo en el verso final se descubre el objeto del poema como si se tratara de un enigma), opone Valente una dicción en la que predomina cierta discontinuidad.

El poema de Valente evacúa cualquier referencia directa al edificio del monasterio pese a citar el topónimo. Por eso, contrariamente a Diego que exalta un lugar determinado, se puede leer el poema valenteano yendo más allá de la demitificación ideológica. Sustituye el edificio prestigioso por un paisaje pobre que manifiesta una historia humana compartida por muchos pero apartada de la memoria oficial, la de los hombres explotados, más globalmente es la de la condición humana que sufre injusticias sociales. El paisaje de Silos, a pesar de la determinación conllevada por el topónimo, se convierte así en paisaje universal. 


\section{Pancorbo: el antipaisaje} ejemplo de topónimo con el cual el poeta procede a una deconstrucción del mito de Castilla como heroicidad cristiana. Para ello construye un paisaje cuya dimensión paradójica surge desde el inicio.

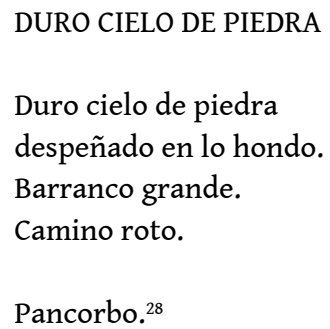
esencialización del paisaje, introduciendo una forma de eternidad ahistórica. La dicción de una voz impersonal agudiza la impresión de estar frente a la foto de un paisaje estancado para siempre. Dominan los efectos sonoros de las aliteraciones duras que recalcan el semantismo de lo mineral y hostil. El paisaje se asemeja a un caos, un montón de ruinas, algo derrumbado que impide anidar cualquier esperanza, desde el cielo cerrado cual una muralla ${ }^{29}$ hasta la ruptura del camino, dos cierres rotundos que afirman la imposibilidad de un más allá, celestial como terrenal.

Tanto la imagen inicial como la última concretan la abolición de un posible horizonte. Es relevante observar cómo la aporía discursiva la prepara: la voz poética se va agotando pasando del heptasílabo inicial al pentasílabo para acabar con un trisílabo. El blanco sonoro y tipográfico materializa en la página la interrupción del camino, el muro que se alza brutal. El trisílabo mediante la rima asonántica le da mayor presencia ("roto/ Pancorbo"). Esta identificación repentina y brutal reintroduce una dimensión histórica en un paisaje que solo era materia y formas. El desfiladero de Pancorbo, único paso de Castilla (Burgos) al norte, única ruta hacia Europa, siempre ha tenido un interés militar y estratégico a lo largo de la historia, desde las invasiones y la Reconquista. En aquellos años 1950-1960 el poema muestra con esta imagen paisajística el aislamiento del país impuesto por la dictadura franquista, la dureza del mismo (sugerido también por el título del libro Breve son). Este paisaje caótico, casi mutilado dice concreta y metafóricamente la imposibilidad de cualquier esperanza y futuro. Traduce el rechazo de la apertura a lo otro, materializa el monolitismo mental y sensible de un país, ese paisaje desesperanzador constituye un antipaisaje siendo ni un "hecho territorial" tampoco "un lugar estetizado" 30 en el sentido más corriente de la palabra. Al construír este paisaje tan duro, el poeta elabora tanto un testimonio como un antidiscurso al de la iglesia católica, respaldo del régimen.

Obviamente encierran los paisajes aquí una dimensión testimonial. Lo relevante está en la tensión que se crea entre lo determinado y lo indeterminado, propicia a una lectura singular y universal a un tiempo. Valente procede a una lectura crítica del paisaje

L'Âge d'or, 10 | 2017 
"cristalizado" 31 por el discurso dominante; deconstruyéndolo logra aislar y revelar los valores ocultos que lo fundan.

Estos dos ejemplos del primer libro parecerían darle la razón a la crítica que limita globalmente la vertiente testimonial a Punto cero. Sin embargo, la obra valenteana hasta el último libro Fragmentos de un libro futuro (2000) invita a reconsiderar esa lectura canónica impuesta por la facilidad, lo mismo que las publicaciones recientes (2014) de la Cátedra Valente (Valente vital) que dan a conocer las actividades de un ciudadano implicado en la "cité" rompiendo con la imagen de un Valente transcendental, en pos de una pureza artística aislada del mundo contingente.

\section{Función memorialística y universal: "el lugar del canto}

Para seguir con la lógica anterior será interesante partir aquí también de un topónimo, el de Víznar, pueblo de las estribaciones de la sierra andaluza conocidísimo hoy por ser el lugar del asesinato del poeta Federico García Lorca en agosto de 1936.

El título situado al final a la manera de un haiku "(Víznar, 1988)”32 propone una doble determinación, espacial y temporal. Formalmente se trata de un poema en prosa, narrativo al principio y a continuación dialogado. Cuenta una visita al barranco de Víznar, reconstituye el encuentro con familiares de represaliados, desaparecidos y hoy olvidados. Rápidamente oímos las dudas de las familias, sus quejas y la respuesta del yo lírico.

DESDE Granada subimos hasta Víznar. Vagamos por el borde sombrío del barranco. - ¿Dónde?, decíamos. Era el otoño. Las hermanas, las viudas, los hijos de los muertos venían con grandes ramos. Entraban en el bosque y los depositaban en algún lugar, inciertos, tanteantes. ¿En dónde había sucedido ? - Lo mataron a él, decía la mujer, pero aquí también mataron a otros muchos, a tantos, a eso que ahora nadie recuerda. - Él ya no es él - dije. Es el nombre que toma la memoria, no inextinguible de todos. ${ }^{33}$

\section{(Víznar, 1988)}

El acierto del poema y su alcance consiste en proponer un testimonio que parte de un paisaje natural identificado por su nombre, incluso por su localización, Granada, y asimilable inmediatamente al asesinato de Lorca, pero evitando mencionarlo.

Estriba la construcción del paisaje en una tensión fuerte entre la determinación toponímica y la indeterminación casi total de los elementos enumerados: no son sino tópicos en el sentido primero de la palabra, "el barranco, el bosque". Es un paisaje escueto hecho de un toque único "el borde sombrío del barranco". Se sugiere el dolor de la ausencia, el duelo imposible ante la desaparición, ante el asesinato sin castigar, ante la amnistía de los asesinos, sin citar nunca al desaparecido ni las circunstancias, haciendo de la desaparición peculiar de Lorca un caso emblemático que se puede universalizar. El barranco de Víznar se convierte así en un paisaje memorialesco: por su mismo vacío hace dolorosamente presente la ausencia de los represaliados. Se pone de realce la divagación del grupo y de las familias que andan buscando con preguntas directas “¿dónde?". Por esta carencia trágica y lo banal del paisaje (no hay nada que ver), por esta incertidumbre (los visitantes repiten preguntas), Víznar evidencia y plasma la verdad tangible de la desaparición frente al olvido. 

muerte de un poeta. La respuesta del yo lírico hablando insistentemente de "Él" rechazando la identificación remite tal proceso de mitificación: el mito da plasticidad, flexibilidad y apertura a lo otro, a lo universal mientras preserva lo propio y singular. Ese "Él" designa tanto a un individuo Lorca como a los demás represaliados: "Él ya no es él dije. Es el nombre que toma la memoria, no inextinguible de todos" ${ }^{34}$. El poeta-mito se ha convertido en un hombre singular lleno de gentes como diría Juan Gelman. Lo mismo pasa con el paisaje: Víznar se convierte en "el lugar del canto" ${ }^{35}$ por decirlo con palabras valenteanas, o sea que el poema propone "una meditación sobre la muerte de cuya universal proyección es inseparable sustancia una entrañable vinculación de lugar"36. La evocación de la ceremonia ritual (la ascensión, el cortejo, las flores, las lloronas) contribuye a anclar el paisaje en esta doble dimensión de un "singular indeterminado" 37 : el mismo poema lo designa como "algún lugar" ${ }^{38}$ manifestando por esta banalización la doble dimensión contradictoria y complementaria. Es esta misma tensión interna al paisaje valenteano la que lo transforma en lugar relacionado con la experiencia individual y colectiva.

\section{El deshacimiento: estética de la indeterminación singular}

Aunar lo singular y lo indeterminado conduce al desprendimiento, a lo que el poeta nombra deshacimiento. El paisaje hace tangible la presencia y la realidad de la ausencia mediante la actitud de contemplación que adopta la voz poética. No se trata de poseer el paisaje abarcándolo todo sino de sentirlo e intuirlo, ir a lo esencial quitando lo anecdótico o local pero preservando lo inmediato. Lo mismo que el haiku o el fragmento es captación de la inmediatez de las cosas, especialmente las más humildes. La historia íntima se manifiesta mediante elementos paisajísticos aislados, apenas esbozados, pero identificables por el lector o identificados por el autor (en el título). Tal es el caso de paisajes gallegos o ingleses. Por cobrar casi siempre otra dimensión, por ejemplo un valor intertextual, escapa el paisaje de los límites estrictamente biográficos. Así el río evocado en la meditación del yo lírico cuando el entierro del padre ${ }^{39}$, enlaza evidentemente con el río simbólico manriqueño, topos del tempus fugit, lo mismo que remite a los paisajes de Rosalía de Castro y al río sar que se encuentran tanto en Punto cero como en Fragmentos de un libro futuro. Valente no se conforma con deconstruir ni construir tan solo un paisaje tal como se suele entender convencionalmente, porque por una parte practica una estética del esbozo, de la pincelada que queda sin acabar, por otra parte, porque juega con las múltiples dimensiones que encierra su esbozo de paisaje. Así la muy fugaz evocación del paisaje urbano de Oxford un primero de mayo ("May Day, 1956") ${ }^{40}$ y la del lago de Ginebra (sin identificar ${ }^{41}$ ) parten de un dato personal (la figura de Antonio, el hijo muerto que nació en Oxford y murió en Ginebra) pero superan lo estrictamente íntimo y cobran un significado amplio: el dolor ante la ausencia. Es experiencia propia que se reúne con la experiencia universal. El elemento paisajístico se inserta en un planctus, en una meditación acerca del memento mori, sobre el tiempo irremediablemente pasado.

Frente al paisaje, el yo lírico siempre intenta captar la presencia sensible del momento, captar lo efímero inmediato para eternizarlo. La búsqueda, la indagación de una presencia, de una inmediatez del cosmos se hace cada vez más intensa en la segunda parte de Punto cero.

L'Âge d'or, 10 | 2017 
¿Cómo podría adentrarme más en este otoño,

cómo podría a lo menos visible

entrar desde los oros

de tu feraz recogimiento, madre

naturaleza ? ${ }^{42}$

La contemplación del paisaje se expresa por visiones sensuales de los elementos naturales construyendo un paisaje erótico luminosamente misterioso:

Tiende su luminoso cuerpo el aire

y en su declive roza

el sol los incendiados cuerpos,

viejo mastín celeste,

con su luz más secreta. ${ }^{43}$

En Fragmentos de un libro futuro, "Cabo de Gata" es un poema emblemático de este proceso en que la experiencia erótica y la poética llegan a fundirse como es el caso también con la mística. Se anudan y se compenetran como en un acto sexual recordando así que éste es forma de conocimiento en la Biblia ${ }^{44}$. El poema "Orillas del Sar" ${ }^{45}$ evoca el poder de la relación erótica en un deshacimiento que conduce a un nacer:

Era tu forma un deshacimiento.

Brotar.

Fluir.

Abandonarse.

El cuerpo-río, el agua-mujer forman un solo paisaje que el yo lírico nombra "lugar" o sea un paisaje hecho tiempo y memoria:

$[\ldots]$ para nacer de ti aquella tarde de qué lugar, qué tiempo, qué memoria.

\section{A manera de conclusión: el paisaje, memoria y deshacimiento}

La obra valenteana encierra inflexiones, evoluciones pero no bifurcaciones, tampoco abandonos aunque sí tendrá sus "puntos de ceguera" y sus contradicciones ${ }^{46}$. La principal de éstas está entre la afirmación del tiempo como discurrir ontológico e histórico y la aspiración al deshacimiento. El tratamiento del paisaje en Valente se puede leer a la luz de esta tensión entre determinación e indeterminación, de la articulación entre la inscripción en lo histórico y un movimiento exílico.

Si en primeras instancias el motivo del paisaje parece poco presente en la obra, es pura ilusión, se debe a la estética de concentración y fragmentación y porque siempre rehuyó Valente de lo ornamental al que demasiadas veces se asocia el paisaje. En su obra delimita y limita el paisaje a lo estrictamente necesario a unos pocos elementos. Su propuesta estética se aproxima a la del arte oriental en que la totalidad se revela mediante fragmentos, incluso por el vacío; la creación es revelación a través del esbozo, de la forma incompleta o inacabada. No es mutilación sino como lo analiza François Cheng ${ }^{47}$ una manera otra de sugerir la totalidad: en el cuadro el vacío actúa como una señal, es un elemento activo que invita a entrar en el paisaje pintado y le da vida. La aproximación a la pintura china, digamos extrema oriental, que es esencialmente pintura paisajística permite entender mejor la estética de Valente en su tratamiento del paisaje: « Devant de 
tels tableaux, même un spectateur innocent sent confusément que le vide n'est pas une présence inerte $[. ..] »^{48}$.

Tempranamente (1968), en el libro de microrrelatos El fin de la edad de plata, Valente proponía el apólogo del cuadro sin acabar destinado al emperador. Constituye este microtexto un auténtico manifiesto estético, aboga por la forma artística aparentemente sin acabar cuando, de hecho, esta forma ya lleva en sí la totalidad para el que sabe mirar. Converge tal apólogo hacia el postulado de la modernidad. Supone un lector/espectador capaz de entrar en el paisaje, hacerse paisaje como Bachelard también lo afirmaba o como lo sugiere el título de la antología valenteana Entrada en materia. Varios poemas o títulos de Valente indican tal aspiración a la penetración, lo que supone destruir la visión externa del paisaje para llegar a conocerlo desde dentro antes de cantarlo (reconstruirlo): "Ahora entramos en la penetración" reza el verso inicial de "Territorio" ${ }^{49}$. Supone una intensa actividad de pasividad, olvidarse para contemplar y llegar a ver el paisaje. Valente designa este abandonarse el deshacimiento $0^{50}$. En el dominio plástico, existen semejantes propuestas estéticas. Jaume Plensa lo mismo que Eduardo Chillida instalan sus creaciones en espacios públicos, sean paisajes naturales sean paisajes urbanos. El peine del viento por ejemplo, como otras obras del escultor vasco dialoga con el paisaje, revela el paisaje circundante en el que se sitúa y al final casi pasa desapercibido a pesar de su monumentalidad. Hacen del paisaje un espacio de revelación, así lo postulaba José Ángel Valente en su diálogo con el escultor: "La escultura no sería así un apoderamiento del espacio, sino la apertura de un entorno"51. Igualmente en los poemas, Valente desocupa el paisaje, le quita lo anecdótico, lo que sobra, conservando los signos de la memoria. Para rendir homenaje a los republicanos muertos en la Alta Saboya ${ }^{52}$, "[al pie de Glières y ante la roca pura" Valente esboza un paisaje con tan sólo un elemento "la nieve [que] áun dura prodigiosamente/ viva [...]" y así convierte la memoria de "[...] Félix/ Belloso Colmenar, Patricio/ Roda, Gabriel Reynes o Gaby, Victoriano/Ursúa, Pablo Fernández,/ [...]" y un cortejo de muertos que él va enumerando y convocando en "carne nuestra/ palabra,/ historia nuestra que no conocimos/ sangre sonora de la libertad". La progresión de la dicción de lo peculiar e individual a la alegoría final opera un movimiento de universalización del caso español. Pasa de un tiempo histórico a un tiempo humano y ético sin abolir la historia peculiar de los combatientes republicanos pero transformándola en la lucha secular por la libertad. Este poema del segundo libro de Valente ilustra cómo tempranamente Valente aúna la meditación propia a conducir al deshacimiento con el testimonio.

En este caso, el paisaje necesita del arte para hacer visible su significado profundo, históricamente concentrado y humanamente ilimitado. Siempre son (parafraseando al poeta Philippe Jaccottet) Paysages avec figures absentes ${ }^{53}$. Tal paradoja se resuelve dentro de una aproximación que aúna lo sensible y lo inteligible, siendo entonces el paisaje puro lugar del canto, donde se enlazan memoria e historia, lo íntimo y lo colectivo. El Valente místico no excluyó al Valente implicado en el testimonio sobre la historia, siguió fiel a la postulación "Escribo sobre el tiempo presente" sabiendo conciliar esencialidad y temporalidad. Los dos imperativos contradictorios señalados por Antonio Machado en su poética de 1931. Por eso el paisaje de Valente sigue cantando y contando, sigue vivo. 


\section{NOTAS}

1. Coincide aquello a todas luces con la evolución de la escritura de Valente en cuanto a temáticas; no obstante las publicaciones recientes de la Cátedra Valente permiten matizar tal imagen, en cuanto al hombre y en cuanto al poeta. La serie de los tres libros monográficos Valente vital demuestra por su abundante documentación cómo el poeta nunca dejó de comprometerse por causas justas como por ejemplo la ayuda a la inmigración gallega en Ginebra, a la lucha antifranquista, a poetas americanos represaliados (Calvert Casey, Heberto Padilla, Juan Gelman). Intentaremos mostrar cómo también se manifiesta tal implicación solidaria en la creación poética. Claudio, Rodríguez Fer ed., Valente vital, Santiago de Compostela, Publicaciones de la Cátedra de Poesía y estética José Ángel Valente, Universidade de Santiago de Compostela, 2012, 2014, 2017.

2. Eduardo, Martínez de Pisón, "El puesto del paisaje en la cultura", Santiago de Compostela, 2016, [consulté le 11/06/2017)] http://eventia.upf.edu/geohumanidades/paginas/ pagina_188_4.es.html.

3. José Ángel, Valente, “Serán ceniza...” en A modo de esperanza (1953-1954), Punto cero, Poesía 1953-1979, Barcelona, Seix Barral, 1980, p. 13.

4. José Ángel, Valente, "XVI” en Treinta y siete fragmentos, ibid., p. 385.

5. No merece la pena hoy detenerse en comentar esta designación a cuya raíz se desarrollaron polémicas que resultan vanas e infundadas.

6. José Ángel, Valente, ibid., sin página.

7. José Ángel, Valente, "Segundo homenaje a Isidore Ducasse" en La memoria y los signos (1960-1965), ibid., p. 294.

8. José Ángel, Valente, "Silos”, ibid., p 204.

9. La memoria y los signos es el tercero de los diez poemarios que componen este libro. Afirma este título la conexión fuerte entre memoria y escritura. Al decir signos, apunta el poeta su concepción de la poesía como enigma por descubrir y no como comunicación, siendo ésta efecto solo de la escritura y no su blanco. Los ensayos valenteanos reunidos en Las palabras de la tribu establecen tal postulación. José Ángel, Valente, Las palabras de la tribu [1971], Barcelona, Tusquets Editores, 1994.

10. Gerardo, Diego, "El ciprés de Silos", Versos humanos [1925], en Antología poética, Francisco Javier, Díez de Revenga ed., Madrid, Alianza editorial, 2007, p. 56.

11. Teresa, Labarta de Chaves, "Introducción" en Gonzalo, de Berceo, Vida de Santo Domingo de Silos, edición de Teresa Labarta de Chaves, Madrid, Clásicos Castalia, 1972, p. 12.

12. Ibid., p. 9. Gonzalo de Berceo nació en la Rioja hacia fines del siglo XII. El libro Vida de Santo Domingo de Silos se sitúa entre la gesta de la Reconquista y la hagiografía.

13. Domingo Manso de Silos nació en el año 1000 y murió en 1073. Fue miembro del entorno de la corte castellana de Burgos, en época del otro gran héroe castellano Ruy Díaz de Vivar, amigo suyo. Lo apunta Teresa Labarta de Chaves al escribir: "Santo Domingo fue muy favorecido por el rey Fernando I como de sus dos hijos, Sancho II y Alfonso VI [..]"concluyendo « Santo Domingo fue una figura de relieve en la corte castellana de la época ", Teresa, Labarta de Chaves, " Introducción » en Vida de Santo Domingo de Silos, op. cit., p. 12-13.

14. Gerardo, Diego, "El ciprés de Silos", Versos humanos [1925], en Antología poética, op. cit., p. 56.

15. José Ángel, Valente, “Silos”, op. cit., p. 204.

16. Por eso es hoy afamado lugar de senderismo.

17. Gerardo, Diego, “El ciprés de Silos”, Antología poética, op. cit., p. 56. 
18. José Ángel, Valente, “Silos”, op. cit., p. 204.

19. En su "Autolectura de Tres lecciones de tinieblas", escribe Valente: “[...] el eje horizontal es el eje de la historia, el eje de la destrucción, de la soledad, del exilio, del llanto del profeta [...]", no parece desatinado leer en la fórmula del paisaje un eje semejante al de un continuum cronológico. José Ángel, Valente, “Tres lecciones de tinieblas: una autolectura”, Tres lecciones de tinieblas (1980) en Material memoria 1979-1992, Madrid, Alianza tres, 1995, p. 73-74.

20. José Ángel, Valente, "Silos", Punto cero, op. cit., p. 204.

21. Recuerda así Valente que la imagen del monasterio desarrollada en el soneto por Diego conlleva esta dimensión bélica, siendo el ciprés sucesivamente "lanza, flecha, saeta.. por ser lugar emblemático de la Reconquista. Gerardo, Diego", "El ciprés de Silos”, Antología poética, op. cit., p. 56 .

22. Interesa recordar que fue en esos mimos años cuando Jorge Guillén publicó su libro Clamor, cuyo subtítulo era Tiempo de historia, significando así cómo los ruidos de las contiendas del siglo XX (el siglo de los extremos según el historiador Eric Hobsbawm) llegaron a afectar su visión del mundo.

23. Desvía el poeta la expresión conocida "un sol de justicia".

24. Lo que connota la hipálage "sobre su sorda servidumbre" cuyo significado viene agudizado por los efectos sonoros de las aliteraciones.

25. Miguel Hernández llamaba directamente a rebelarse, “¡ Cuántos siglos de aceituna,/ los pies y las manos presos,/ sol a sol y luna a luna,/ pesan sobre vuestros huesos ! [...] Jaén, levántate brava [...] no vayas a ser esclava con todos tus olivares". (Miguel, Hernández, "Aceituneros" en Viento del pueblo, poesía de la guerra, Juan Cano Ballesta ed., Madrid, Cátedra, 1989, p. 95-97).

26. José Ángel, Valente, "Redoble por los kaiowás del Matogrosso del Sur", Fragmentos de un libro futuro, op. cit., p. 29-30. Volveremos luego al tema de la tensión entre referente histórico y aspiración a la negación de la historia mediante la impersonalización o indeterminación.

27. Concluye el poema con esta apertura universalizante y solidaria: “Todas las manos juntas representan/el nuevo nacimiento, el vuestro, el nuestro/ si aún fuese posible / nacer a vuestro lado/ en la tierra sin mal" (ibid., p. 30).

28. José Ángel, Valente, "Duro cielo de piedra" in Breve son, I (1953-1968), Punto cero, op. cit., p. 266.

29. Esta imagen valenteana de un cielo hermético entra en resonancia con la que Blas de Otero elaboró en un poema ("un cielo cerrado a cal y canto") a pesar de una tonalidad y estética distintas: "Alzad al cielo el vientre, oh hijos de la tierra;/ salid por esas calles dando gritos de espanto!/ Los veintitrés millones de muertos en la guerra/se agolpan ante un cielo cerrado a cal y canto." (Blas, de Otero, « Hijos de la tierra », Redoble de conciencia, en Ansia [1958], Madrid, Visor, 2003, p. 141).

30. Eduardo, Martínez de Pisón, "El puesto del paisaje en la cultura", op. cit.

31. Expresión propia de Valente para designar la momificación y esterilización de la palabra por la ideología dominante que institucionaliza y corrompe el lenguaje. Ver los ensayos de la primera parte de Las palabras de la tribu, op. cit., en particular "(Ideología y lenguaje”, p. 55-60.

32. José Ángel, Valente, “(Víznar, 1988)” en Fragmentos de un libro futuro, op. cit., p. 49.

33. José Ángel, Valente, ibid., p. 49.

34. José Ángel, Valente, ibid., p. 49.

35. José Ángel, Valente, "El lugar del canto" en Las palabras de la tribu, op. cit., p. 30-32.

36. José Ángel, Valente, ibid., p. 32.

37. Jacques, Rancière, Malaise dans l'esthétique, Paris, Galilée, 2004, p. 15. La traducción es de la autora.

38. José Ángel, Valente, “(Víznar, 1988)”, Fragmentos de un libro futuro, op. cit. p. 49.

39. José Ángel, Valente, “(Un recuerdo)”, Punto cero, op. cit., p. 193-195.

40. José Ángel, Valente, “(May Day, 1956)”, Fragmentos de un libro futuro, op. cit., p. 52.

41. José Ángel, Valente, “(Hic locus)”, ibid., p. 79. 
42. José Ángel, Valente, “Declinación de la luz”, Punto cero, op. cit., p. 451.

43. José Ángel, Valente, “Días de septiembre en Sinera, 1976”, ibid. p. 452-453.

44. Es de recordar cómo Valente no dejó de implicarse en la lucha por la defensa del paraje natural cuando se instaló en su casa del casco histórico de Almería. Consultar el último volumen de Valente vital, op. cit.

45. José Ángel, Valente, “(Orillas del Sar)”, Fragmentos de un libro futuro, op. cit., p. 79.

46. La expresión la usa José Luis Gómez Toré en una reflexión interesantísima sobre la lectura de José Ángel Valente hoy, su actualidad y actualización ante un canon reductor. Enfoca su introducción al dosier la cuestión de la relación paradójica y tensa de Valente con la historia, hecha de rechazo y necesidad ética. José Luis, Gómez Toré, "Valente en tiempos de miseria. Consideraciones intempestivas", en Dosier Valente "Ángel Valente a partir de cero", José Luis Gómez Toré ed., Cuadernos hispanoamericanos, n763, 2014, p. 6-19. http://www.aecid.es/CentroDocumentacion/Documentos/documentos\%20adjuntos/CH_763.pdf [consultado 04/07/2018).

47. François, Cheng, Vide et plein. Le langage pictural chinois, Paris, Seuil, Points/essais, 1991.

48. François, Cheng, ibid., p. 47.

49. José Ángel, Valente, “Territorio" en Interior con figuras (1973-1976), Punto cero, op.cit., p. 403-404.

50. Así es como se titula el poema dedicado a Juan Goytisolo. José Ángel, Valente, “Deshacimiento " en Fragmentos de un libro futuro, op. cit., p. 86.

51. José Ángel, Valente, "Rumor de límites" en Elogio del calígrafo, Barcelona, Galaxia Gutenberg, 2002 , p. 39.

52. José Ángel, Valente, “Cementerio de Morette-Glières, 1944” en Poemas a Lázaro (1955-1960), Punto cero, op. cit., p. 123-125.

53. Philippe, Jaccottet, Paysages avec figures absentes [1970], Paris, Gallimard/ Poésie, 1976.

\section{RESÚMENES}

A través de unos ejemplos sacados de la obra poética de José Ángel Valente, proponemos una reflexión sobre el espacio que ocupa el paisaje y sus funciones para sacar lo singular de una estética que se funda en la tensión entre deconstrucción y deshacimiento. De tal articulación nace una obra radical que aúna una escritura de la memoria y una estética del desnudamiento.

À travers quelques exemples de paysages extraits de l'œuvre poétique de José Ángel Valente, nous nous proposons de réfléchir à la place qu'occupe le paysage et à ses fonctions afin de dégager la singularité d'une esthétique qui se fonde sur la tension entre la déconstruction et le mouvement de déprise. De cette articulation naît une œuvre radicale qui concilie une écriture de la mémoire et une esthétique du dénudement.

\section{ÍNDICE}

Mots-clés: Valente (José Ángel), paysage, déconstruction, mémoire, déprise

Palabras claves: Valente (José Ángel), paisaje, deconstrucción, memoria, deshacimiento 
AUTOR

CLAUDIE TERRASSON

Université Paris-Est-Marne-La-Vallée, LISAA (EA 4120) 